\title{
A Gestão Tributária no Controle à Sonegação Fiscal
}

Gilmar Gomes de Oliveira ${ }^{1}$; Emanoel Silva Antunes ${ }^{2}$

\begin{abstract}
Resumo: Considerando a alta carga e intricado de regras do sistema tributário brasileiro, percebe-se a importância da gestão tributária como ferramental para a pressuposição dos custos tributários, tomando assim imprescindível para a opção da forma de tributação menos onerosa. Este estudo teve o objetivo de discurtir a importância da Gestão Tributária na redução da carga tributária e o controle à Sonegação Fiscal a partir de uma metodologia de levantamento bibliográfico. A seleção do tema desta pesquisa se deu mediante experiência pessoal do autor, bem como, interesse do meio academico em se discutir assuntos que impactam a sobrevivencia e competitividade empresarial. O principal resultado do artigo destaca que a importancia e os impactos positivos que o planejamento tributário traz para as empresas.
\end{abstract}

Palavras-chave: Sistema tributário brasileiro. Gestão tributária. Levantamento bibliofráfico.

\section{Tax Management in the Control of Fiscal Withhold}

\begin{abstract}
The rate of the tributary Brazilian, such as behaviour distribution for judging to a pressuposition of costs tributary, having such imprecindible for an option of taxation less onerosa.. This study aimed to discuss the importance of Tax Management in reducing the tax burden and controlling tax evasion from a bibliographic survey methodology. The selection of the theme of this research was based on the author's personal experience, as well as the academic community's interest in discussing issues that impact business survival and competitiveness. The main result of the article highlights the importance and positive impacts that tax planning brings to companies.
\end{abstract}

Keywords: Brazilian tax system. Tax management. Bibliographic survey.

\section{Introdução}

O presente estudo tem o enfoque em Gestão Tributária que visa o controle, a adequação, dilineação e revisão do planejamento tributário, a qual deve orientar procedimentos assertivos a serem adotados dentro das empresas. Ao realizar o planejamento fiscal de forma apropriada na efetivação do cômputo do total dos tributos a pagar, pode suprimir despesas supérfluas e ainda eliminar os passivos tributários, o que possibilita a maximização dos resultados tanto econômicos como financeiros.

\footnotetext{
${ }^{1}$ Acadêmico de Direito (FACAPE). Contato: gilmargomes.oliveira@ hotmail.com

${ }^{2}$ Especialista em Direito Tributário (IBPEX)Bacharel em Direito (FACAPE). Bacharel em Ciências Contábeis (FACAPE). Professor Auxiliar (FACAPE). Contato: emanoelsantunes@gmail.com
} 
Nesta perspectiva, o planejamento nos remete primeiramente a uma idéia de antecipação dos fatos, ou seja, busca-se evitar a ocorrencia do fato gerador da obrigação tributária, jamais ocuta-lo. Planejar na atividade empresarial, é conduzir uma previsão de como os fatos podem impactar no orçamento e em sua gestão, abrindo dessa forma, uma gama de possibilidades para desenvolver métodos e estratégias para atingir objetivo desejado.

Neste sentido, os empresários para enfrentar seus concorrentes, devem criar estratégias administrativas na execução do seus negócios, que estejam aliadas ao planejamento conforme o que é proposto, então, sempre conforme a missão, os propósitos e objetivos estratégicos dos seus sócios administradores.

A busca incessante por minimizar custos e maximizar resultados, base da teoria neoclássica, não deve trair a conduta do empresário, jamais se deve adotar condutas lesivas ao erário público e acima de tudo criminosas, mas sim implantar correto planejamento tributário, procurando reduzir os tributos de forma lícita, evitando pagar além do devido, o que é conhecido como elisão fiscal.

Em contrapartida, a escolha errada na forma de apuração e recolhimento de tributos, pode gerar muitas dificuldades e resultar em prejuízo, já que, uma vez escolhida a forma de tributação no ano do calendário, ela será adotada de forma irretratável durante todo o ano, ou seja, não poderá ser alterada durante o exercício social.

De antemão, para conseguir o êxito na Gestão Tributária da empresa, somente é possível, se o empresário e os responsáveis dessa área, estiverem atentos à legislação vigente e suas alterações, como por exemplo, a Lei n. ${ }^{\circ}$ 8.137/90. Também deve ser profundo conhecedor de todas as situações operacionais para a eficaz projeção e aproveitamento das lacunas que a legislação oferece para redução da carga tributária.

Com base nessa premissa, o presente trabalho aborda de forma dinâmica a Gestão Tributária aplicada no controle e fiscalização dos tributos, apresentando as possibilidades de economia, dentro da realidade tributária brasileira.

A área do conhecimento abrangida no presente artigo é a Gestão Tributária com ênfase no planejamento tributário, o que viabiliza de forma menos onerosa o pagamento de tributos, impedindo a sonegação, ou seja, o cometimento de crime contra a ordem tributária.

Diante deste contexto, esta pesquisa tem a proposta de responder à seguinte problematização: devido aos rescente noticiários sobre a corrupção sistêmica no cenário 
governamental e empresarial no Brasil, surgiu a necessidade de questionar a gestão tributária nas empresas, com as seguintes perguntas:

- De que modo poderá ser feito o planejamento tributário nas empresas, com utilizações de estratégias para a evitar a sonegação e o desvio fiscal?

- Que meios legais o empresário poderá utilizar na redução e na fiscalização dos tributos recolhidos, de forma a alcançar os própositos e objetivos dos sócios administradores?

Nessa perspectiva, este artigo tem como objetivo discurtir a importância da Gestão Tributária na redução da carga tributária e o controle à Sonegação Fiscal.

Justifica-se este estudo, diante dos atuais acontecimentos no cenário político e econômico de nosso país. É notória a corrupção estampada nos telejornais, à elevada carga tributária e os casos da sonegação de tributos, sem contar as propinas paga pelos empresários das grandes empreiteiras aos servidores públicos no Brasil. Neste diapasão é fundamental entender o Direito Tributário e toda a legislaçao, sempre tendo como parâmetro a interpretação jurisprudencial.

Neste sentido, esta pesquisa contempla discussões na área do Direito Tributário, buscando esclarecer dúvidas relacionadas a Gestão Tributária, detacando temas como o planejamento tributário e a sonegação fiscal no ambiente empresarial.

Trata-se de uma temática ampla, o que faz necessário ser estudada de forma crítica, colocando assim, as suas principais caracteristicas para que haja o entendimento da prática do direito tributário como ato licito, de legalidade e honestidade em conformidade ao Direito Público.

Neste contexto, a delimitação do artigo é relacionada à discussão sobre o Direito Tributário, a tributação fiscal e a Lei 8.137/1990.

A hipótese do estudo é de que a licitude na apuração dos tributos devidos, deve ser encarada como um dever jurídico pelos empresários brasileiros. Se há intenção de sobrevivencia, deve-se respeitar a legislção, no intuito de evitar penalidade cíveis e penais.

Nas palavras de Machado (2007), a tributação é a ferramenta de que o Estado tem empregado da economia capitalista para sua manutenção. 


\section{Fundamentação Teórica}

\section{A Gestão Tributária no Controle à Sonegação Fiscal na Empresa}

Acontecimentos atuais publicados nas capas de jornais, transmitidos pelos telejornais e na internet, apresentam um cenário de corrupção sistêmica no Brasil. Dados da pesquisa da Confederação Nacional dos Transporte - CNT (2017), mostram que a percepção da população em relação a ocorrência de corrupção no país, é atualmente de 46,8\%, no entanto, em relação aos empresários a percepção é de 4,2\%.

De acordo com o novo Código Civil brasileiro em seu Art. 186 (BRASIL, 2003), ato ilegal ou ilícito é "aquele que, por omissão ou ação voluntária, imprudência ou negligência, infringir um direito e provocar dano a outrem, ainda que exclusivamente moral".

O Sindicato Nacional dos Procuradores da Fazenda Nacional (SINPROFAZ, 2016), denunciou naquele ano, que, ao menos, meio trilhão de reais são sonegados por ano. As grandes empresas respondem por boa parte desse imenso volume de sonegação, sempre utilizando de esquemas sofisticados, como a lavagem de dinheiro, ou seja, práticas de atos ìlicitos com fins de obter lucro de forma ilegal.

Corroborando com este pensamento, segundo Pellizzari (2002) citado por Franco (2015, p. 04), comentam que:

\footnotetext{
É da essência da prática das multinacionais a evasão fiscal. Tanto é assim que elas se instalam em outros países, que não os seus de origem, para, além de conseguirem mão-de-obra barata, terem os estímulos que o governo anfitrião oferece (isenções, prorrogações de pagamentos de impostos, concessão de incentivos, empréstimos a longo prazo com juros baixos), e poderem, através de manipulações e fraudes, sonegar impostos. Através do subfaturamento e do imobilizado caduco, pode-se identificar os níveis de sonegação das multinacionais.
}

Entre os danos da sonegação fiscal, de acordo com o presidente da SINPROFAZ (2016), encontra-se a concorrência desleal provocada pelas grandes empresas sonegadoras, que penaliza os micro e pequenos empresários. Em suas palavras “a questão não é o tamanho, mas sua composição". Basta lembrar que o sistema tributário brasileiro é um dos mais complexos do mundo.

O sistema tributário brasileiro apresenta-se como um dos mais complexos do mundo, com cerca de aproximadamente sessenta e um tributos, entre impostos, taxas e 
contribuições. Além disso, as obrigações acessórias trazidas com os impostos são consideradas um algo a mais que as empresas têm de cumprir e que toma grande parte do tempo que poderiam ser gastos no processo produtivo (SANTIAGO, 2006 apud HENRIQUE, 2011, p. 31-32).

Neste sentido, Henrique (2011) ainda complementa sobre este sistema tributário como muito oneroso, ineficiente e complexo, pois existe inumeros tributos nas três esferas de governo.

Nesta perspectiva, pode promover a sonegação fiscal, acarretado pelas irregularidades na apuração, reconhecimento e pagamento dos tributos. Tributo conforme o art $3^{\circ}$ da Lei $n^{\circ}$ 5.172/66 do CTN, "é toda prestação pecuniária compulsória, em moeda ou cujo valor nela se possa exprimir, que não constitua sanção de ato ilícito, instituída em Lei e cobrada mediante atividade administrativa plenamente vinculada" (BRASIL, 2017).

\section{Direito Tributário, Privado e Público}

O Direito Tributário, segundo Oliveira e Costa (2010,), tem como escopo zelar pelas medidas adotados pelo Estado para arrecadar os tributos necessários para a atividade público, visando sempre o interesse social. Nessa perspectiva, o governo procura promover a responsabilidade social, aplicando a cobrança de impostos, taxas e contribuições de forma legais.

Neste contexto, é de fundamental importancia levar em conta o princípio da Legalidade, que é um dos pilares do Estado democrático.

O direito tributário brasileiro consagra duas regras básicas pertinentes a esse princípio: (a) reserva formal - indispensabilidade de ato legislativo como veiculo para instituir ou aumentar tributo; (b) reserva absoluta - a lei deve conter todos os elementos do tipo tributário. O tipo tributário também manterá sua completeza na ausência de alíquota, quando o tributo é expresso em quantia fixa (CASSONE, 2002 apud LONGO, 2010, p. 43-44).

Neste sentido, Ichihara (1991, p. 57) define o princípio da legalidade:

É o que protege o empreendedor dos abusos administrativos, pois a matéria tributária está vinculada a uma tipificação legal, assim como o direito penal. Entretanto, através de atos normativos, os órgãos da administração pública estão 
tratando os tributos como normas penais em branco, pois alteram sua interpretação e destinação com a desculpa de explicar a lei e com isso instauram caos tributário. Pois na ausência de um conceito sobre a forma de proceder em relação a determinada arrecadação, surgem várias consultorias exarando parecer, contadores temerários por seus atos, colocando o gerador da arrecadação para o estado com medo de ser preso pelo suor do seu próprio trabalho.

O Direito Privado, segundo Oliveira e Costa (2010, p. 18) é um ramo do Direito que orienta e legisla sobre as relações entre atividades privadas, portanto, é nesse Direito que as pessoas (físicas ou jurídicas) se encontram no mesmo patamar legal, diferente do que ocorre com as relações do Direito Público, uma vez que o Estado possui a prerrogativa de representatividade do interesse coletivo.

Com isso, seja no Direito Público ou Privado, os responsáveis pela apuração dos tributos, devem ter consciencia de que, quem elimina um tributo está cometendo um ato ilícito, quem reduz a carga tributária através da evasão fiscal comente crime (MACHADO, 2007).

A Elisão Fiscal ou Elusão Fiscal, segundo Leal (2014) citado por Orsini (2016), acontece quando uma empresa disfarça uma operação jurídica, com o objetivo de dissimulaçar ou manipular o fato gerador do tributo, portanto, configurando-se como uma forma lícita, para esquivar de forma artificial da cobrança do tributo.

Para Côelho (1999) citado por Rizzi (2017), a diferença entre elisão e evasão, é que esta adota caminhos ilícitos, como fraude de documentos, simulação de operações, já aquela adota artificios lícitos, ou seja, lacunas da lei, para contornar alguma exigencia, uma vez que não está vedado pelo legislador.

\section{A Sonegação Fiscal nas Empresas}

Neste sentido, a sonegação fiscal no entende de Franco (2015, p. 38) pode ser caracterizada quando:

O contribuinte utiliza-se de procedimentos que infrinjam espontaneamente a lei fiscal ou o regulamento fiscal. A alta carga tributária no Brasil é um dos fatores determinantes para sonegação fiscal. Algumas empresas recorrem à sonegação para sobreviver mesmo sabendo tratar-se crime contra a ordem tributária, pois entendem que se cumprirem a legislação à risca, acabarão por inviabilizar o seu negócio. 
Sob esta pespectiva, Freitas (2017), comenta que no intuito de combater a Sonegação Fiscal, esta conduta foi definida como uma prática criminosa pela Lei 8.137/1990. Esta norma definiu em seus artigos $1^{\circ}$ e $2^{\circ}$, os crimes contra a ordem tributária. Em resumo, é crime o ato de suprimir e reduzir tributos, contribuição social e qualquer acessório, mediante as seguintes condutas:

I - omitir informação, ou prestar declaração falsa às autoridades fazendárias;

II - fraudar a fiscalização tributária, inserindo elementos inexatos, ou omitindo operação de qualquer natureza, em documento ou livro exigido pela lei fiscal;

III - falsificar ou alterar nota fiscal, fatura, duplicata, nota de venda, ou qualquer outro documento relativo à operação tributável (Ibidem, p. 13)

Caso, seja comprovado o crime de sonegação fiscal, poderá acarretar em uma pena de reclusão de 02 (dois) a 05 (cinco) anos, além de multa, nas inflações citadas no Artigo $1^{\circ}$ e penas de reclusão de 06 (seis) meses a 02 (dois) anos (Ibidem).

Neste contexto, poderá ocorrer a sonegação fiscal simples, dolosa ou fraudulenta que, na interpretação de Franco (2015. p. 42):

\begin{abstract}
A primeira é a que resulta da falta de pagamento do imposto, sem qualquer malícia ou sem o emprego ardil ou fraude. É o simples não pagamento. A segunda é a gerada da fraude ou da má-fé do contribuinte, que usa meios, manobras, ou ardis para se furtar ou se subtrair do pagamento do imposto. Assim, é considerado crime contra a ordem tributária qualquer ação ou tentativa de evitar total o parcialmente o pagamento de tributos utilizando-se de meios ilegais para tanto.
\end{abstract}

Seja qual for a sonegação fiscal, pode ser considerado como desvio de conduta e não justifica a sua prática, mesmo, com o Brasil apresentando alta carga tributária. Franco (2015) ao longo da sua pesquisa comenta que, "as diversas formas que a alta carga tributária contribui para sonegação fiscal, e para uma série de outras distorções econômicas, além de diversos outros problemas".

No entanto, como realizar o controle e fiscalização dos tributos? Essa resposta poderá vim de várias observações, e uma dela é a Gestão Tributária.

Caso o empresário opta por não trabalhar de forma ilícita, poderá recorrer ao planejamento tributário, como meio para aliviar o peso dos tributos, o qual pode contemplar mecanismos legais, e dessa forma, reduzir a elevada carga tributária. 


\title{
Gestão Tributária e o Planejamento Tributário
}

De acordo com Bergamini (2012), a Gestão Tributária é de suma importância no mundo empresárial, principalmente como ferreamente de planejamento e controle da tributação, isto devido a elevada carga tributária incidente sobre os negócios que ocorrer em território brasileiro.

\begin{abstract}
As grandes empresas, na busca pela economia de tributos, recorrem à gestão tributária, não somente para que tenha a segurança de estar percorrendo por caminhos lícitos na redução de encargos tributários, como também para evitar que um planejamento fiscal mal estruturado acabe por configurar em um crime contra a ordem tributária (LONGO, 2010, p. 36)
\end{abstract}

Neste sentido, para Orsini (2016), é possível não sonegar quando se tem uma Gestão Tributária que objetive adequar, planejar e revisar procedimentos, isto é, visa o controle, a gestão e a estratégia empresarial, não somente o desenvolvimento de simples atividades.

Sob está ótica, há necessidade do controle da tributação pelo aplicação correta do Planejamento Tributário, com enfoque na definição da fronteira entre o que é legal e lícito, com o designio de promover a diminuição do peso da carga tributária no orçamento empresarial (RIZZI, 2010).

O planejamento Tributário tornou-se de fundamental importância para as empresas, devido à legislação tributária brasileira, adotar um número excessivo de leis e de constantes alterações. Portanto passa a ser vista como complexa, o que dificulta aos empresários a promover a interpretação, assim como se manter atualizados em virtude dos diversos influenciadores na gestão empresarial de forma específica (SIQUEIRA; CURY; GOMES, 2011, p. 184-185).

De acordo com Souza e Pavão (2017), o a gestão tributária não pode ser autrdido com a sonegação fiscal, pois planejamento envolve escolhas entre diversas opções legais e lícitas, sempre conduzindo para os melhores resultados.

Este autores, apontam três finalidades para ser realizado no exercício desse planejamento: "evitar a incidência do tributo, reduzir o montante do tributo devido e postergar o momento de sua exigibilidade" (SOUZA; PAVÃO, 2017, p. 6).

No entanto, para Orsini (2016), para que esse planejamento seja desenvolvido, é necessários um estudo prévio que se modificam conforme a atividade empresarial. Assim, aponta para os seguintes aspectos: 
A interpretação da lei quanto a hipótese de incidência dos tributos, ou seja, a situação abstrata apresenta na lei; A aplicação da hipótese ao caso concreto, em outras palavras, a fato gerador; O gerenciamento do planejamento; $\mathrm{O}$ acompanhamento do mesmo ao longo de sua execução; A defesa prévia e os riscos envolvidos na mesma quanto ao montante que se pretende economizar (Orsini, 2016, p. 4).

Para Souza e Pavão (2017), o planejamento tributário é o instrumento singular que promove economia real para as finanças empresariais, sem nenhuma apreensão quanto ao fisco, pois não haverá complicações uma vez que adota medidas lícitas.

Ademais, caso contrário se houver um equivocado planejamento tributário, segundo Fabretti (2006), resulta em evasão fiscal, que é um mecanismo ilícito de diminuição da carga tributária, que não cumpre as devidas determinações da lei, essa conduta passa a ser classificada como crime de sonegação fiscal, podendo os autores responder pelos seus atos ílicitos contra o Fisco.

Outro ponto fundamental para o controle à sonegação fiscal, está na busca pela simplificação da apuração dos tributos, busca-se esse objetivo na nova reforma tributária, que segundo Franco (2015, p. 46):

As medidas adotadas deverão tornar o sistema tributário mais neutro, ou seja, minimizar distorções nos preços relativos por meio da introdução de impostos gerais e com alíquotas uniformes (principalmente sobre o valor agregado) e desonerar o setor produtivo, com a eliminação das contribuições que incidem em cascata.

Nesta perspectiva, caso a reforma tributária aconteça e possa levar a diminuição da carga tributária, no entender de Henrique (2011, p. 61), teria como consequência:

a) Uma alavancagem no processo produtivo, já que com a diminuição dos impostos mais empresários estariam dispostos a investir no local e gerar novos empregos.

b) Um provável déficit nas conta s do governo, uma que os gastos são altos e necessitam de recursos financeiros para financiar esses gastos.

Corroborando com este pensamento, o SINPROCON (2016), complementa que, no nosso país, a tributação é em sua maioria sobre a renda, não sobre o consumo, o que acaba promovendo ainda mais desigualdades sociais. Logo, uma reforma tributária no Brasil é urgente, bem como um sistema fiscal que promova justiça social. 
Pode-se concluir, que temos um das mais elevadas cargas tributárias do mundo, que apesar desse peso, não se justifica a adoção de práticas de evasão fiscal, como previstas e tipificadas como crimes na Lei 8.317/1990. Apesar das imposições legais, é possível reduzir o impacto dos tributos no resultados economico e financeiro, tudo através da gestão tributária ou simplemente do planejamento tributário. Vale destacar, que enquanto nos crimes de sonegação fiscal o empresário busca ocultar a ocorrência do fato gerador, no planjamento tributário o empresário busca evitar a ocorrencia do fato gerador.

Finalmente, apesar dos escandalos atuais e da pouco credibilidade dos políticos nacionais, não pode os empresários dexar de cumprir seu papel social por meio da justa arrecadação de seus tributos.

\section{Procedimentos Metodológicos}

O método de pesquisa aplicado neste estudo é qualitativo. Com relação aos procedimentos técnicos, o estudo faz uso de fontes bibliográficas e documentais. Embora os métodos de pesquisa documental e bibliográfica envolvam a análise de documentos, eles diferem em alguns aspectos. A pesquisa bibliográfica é uma forma de estudo, enquanto a documental é a análise de textos e documentos.

A metodologia, portanto, é uma pesquisa bibliográfica com os fundamentos metodológicos que serão aplicados para chegar a possíveis soluções e resultados desejados que, aborde principalmente, sobre Gestão Tributária, a tributação fiscal que a empresa deve prestar ao governo brasileiro, o planejamento tributário e a sonegação Fiscal a Lei 8.137/1990 e outros temas relacionada a tématica em estudo.

De acordo com Furasté (2008, p, 33), este tipo de pesquisa "baseia-se fundamentalmente no manuseio de obras literárias, quer impressa, quer capturadas via internet. [..] Quanto mais completas e abrangentes forem as fontes bibliográficas consultadas, mais rica e profunda será a pesquisa".

Nesta perspectiva, enquadra-se em uma pesquisa de natureza aplicada, pois será de acordo com a aplicação da tributação federal que serão obtidos os resultados pelo objeto da pesquisa. Assim, procura a utilização de critérios a serem utilizados, pode classificar a pesquisa em exploratória, descritiva ou ainda em explicativa e, qualitativa. 
A pesquisa qualitativa, conforme argumentos de Minayo (2010), procura demandas muito pormenorizadas e específicas, com um enfoque no nível do fato investigado que não pode ser quantificado e mensurado.

Neste contexto, o presente estudo tem a importância em mostrar a comunidade do curso de direito e aos pesquisadores que tem interesse sobre a temática, as estratégias para a sobrevivência da empresa no mercado, desde que opte por agir conforme as leis e evitar a sonegação de imposto e não procure agir de forma ílicita.

\section{Análise Bibliográfica}

A gestão tributária é um objeto de estudo não somente no âmbito científico mas também, de forma aplicada e empírica pelas empresas que muito dependente de um sério planejamento a fim de reduzir sua carga tributária.

A gestão tributária concetra seu definição ilustrado pelo verbo elidir, que significa evitar. No contexto do tema deste estudo, entende-se como evitar, isto é, no sentido de diminuir a soma total ou dilatar o prazo do pagamento do tributo, por atos ou omissões lícitos do sujeito passivo, anteriores à ocorrência do fato gerador.

Logo, o planejamento tributário é desenvolvido com uma única finalidade: economizar impostos, atentando-se sempre ao princípio da moralidade, ou seja, práticas compatíveis com as normas legais aplicáveis.

Conforme debatido pelos autores bases destacados no capítulo de referencial teórico, pode-se resumir que a gestão tributária possui três finalidade precípuas: (a) evitar cobrança do tributo, adotando medidas que não promovam a ocorrência do fator gerador do tributo; (b) reduzir o montante a recolher, seja a base de calculo ou a alíquota incidente; e (c) delongar o pagamento do tributo, postergando o pagamento sem cobrança de multas.

Sabe-se que a carga tributária no Brasil é altíssima, cerca de $35 \%$ do faturamento das entendides e cerca de $55 \%$ do lucro obtido pelas mesmas. Ao adotar o planejamento tributário, tem-se a intenção de reduzir esse impacto, com uma visão sistemica de todos os tributos incidentes sobre determinada atividade empresarial ou modalidade tributária.

Diferentes estratégias de gestão tributária exigem recursos diferentes. Por exemplo, o gerenciamento de impostos requer conhecimento e recursos exclusivos em comparação com o 
simples atendimento às exigencias tributárias. Embora não tenhamos conhecimento de qualquer evidência empírica, é razoável supor que o planejamento fiscal é mais dispendioso do que a simples execução do pagamentos dos tributos, sem uma análise critériosa adequada a um planejamento tributário. Além disso, a maioria dos gestores tem pouco experiência com impostos, não dominando as lacunas legais que permitem uma elisão fiscal satisfatória.

Destaca-se o impacto do da gestão tributária como um planejamento preventivo considerando a legislação, os atos e fatos administrativos pertinentes à rotina empresarial, com a intenção de examinar e selecionar as possibilidade de minimização do ônus tributário, no que concerne a onerosidade ou aos prazos de recolhimento dos tributos. Adicionalmente, esse ferramental legal e contábil pode trazer vantagens para o processo de tomada de decisão, com o escopo de assegurar melhores conjunturas economicas e financeiras para as empresas.

\section{Considerações Finais}

A profissionalização da gestão tributária nas empresas é essencial para a competitividade e permanência no mercado. Conclui-se, portanto, que o planejamento tributário deve ser desenvolvido de forma preventiva, de modo a identificar maneiras legais que possibilitem a reduzir ou eliminar o ônus tributário.

Ultimamente a tributação sobre os resultados empresariais é aplicada conforme os regimes de tributação: Lucro Presumido, Lucro Arbitrado ou Lucro Real. Usualmente, as empresas são orientadas a selecionar ou o Lucro Presumido ou o Lucro Real, já que o Lucro Arbitrado, teoricamente, devido a imprevisibilidade do quantitativo do lucro na atual economia brasileira, é a forma mais onerosa de tributação, aplicada inclusive pela fiscalização fazendária ao identificar alguma irregularidade na apuração dos tributos.

Diante de sua complexidade, a gestão tributária deve ser desenvolvida profissional competente, com especialização em Direito e Contabilidade e com profundos conhecimentos tributários, fiscais e contábeis, caso contrário, a empresa pode estar fadada ao fraco, ao se planejar incorretamente quanto aos tributos a pagar. O incorreto recolhimento de tributos pode acarretar ainda mais pagamentos de impostos, moras e multas, e consequentemente, maiores despesas e dispêndios desnecessários de recursos monetários da empresa. 
Conclui-se, portanto, diante da discussão teórica e aplicada deste estudo, que a gestão tributária se estabelece como relevante instrumento a ser adotado pelas empresas que cumpre amplamente as diretrizes e normas da legais com o escopo de diminuição de pagamentos de impostos ao governo.

\section{Referências}

BRASIL. Novo Código Civil Brasileiro. Lei 10.406, de 10 de janeiro de 2002. São Paulo: Revista dos Tribunais, 2003.

BRASIL. Lei no 5.172, de 25 de outubro de 1966. Dispõe sobre o Sistema Tributário Nacional e institui normas gerais de direito tributário aplicáveis à União, Estados e Municípios. Disponível em: <http://www.planalto.gov.br/ccivil_03/leis/L5172.htm>. Acesso em: out. 2017.

CNT, Código Tributário Nacional. Pesquisa CNT/MDA: relatório síntese. Rodada 133. 2017. Disponível $\quad$ em:< http://cms.cnt.org.br/Imagens\%20CNT/PDFs\%20CNT/Pesquisa\%20CNT\%20MDA/Integra\%20CNT MDA\%20Fevereiro\%202017.pdf >. Acesso em out. 2017.

FABRETTI, Láudio Camargo. Contabilidade Tributaria. 10. ed. São Paulo, Atlas, 2006 p. 32.

FRANCO, Luciana Viana da Silva. A sonegação fiscal como sonsequência da alta carga tributária brasileira. Pós-graduação de Direito Tributário e Finanças Públicas da Escola de Direito de Brasília - $\quad$ EDB/IDP, $2011 . \quad$ Disponível:< http://dspace.idp.edu.br:8080/xmlui/bitstream/handle/123456789/1820/Monografia_Luciana\%20Vian a\%20da\%20Silva\%20Franco.pdf?sequence=1>. Acesso em nov. 2017.

FURASTÉ, Pedro Augusto; Normas Técnicas para o Trabalho Científico: Elaboração e Formatação. Explicitação das Normas da ABNT. 14 ed - Porto Alegre: 2008

GIL. Antonio Carlos. Como Elaborar Projetos de Pesquisa. 4 ed. São Paulo: Atlas, 2002.

HENRIQUE, Marco Antonio. Gestão pública e a questão tributária: um estudo sobre o ISS e o IPTU nos municípios de São José dos Campos e Taubaté. 2011. 161f. : il. Dissertação (mestrado). Universidade de Taubaté, Departamento de Economia, Contabilidade e Administração

JASPER, F. Enquanto reforma não sai, país cria 50 normas tributárias ao dia. 2007. Disponível em: <http://www.depacom.org.br/informativos/2007/621_05_10_07.htm>. Acesso em out. 2017.

LONGO, A. K. F. O impacto econômico negativo do planejamento tributário nas empresas. Universidade Federal do Rio Grande do Sul. Porto Alegre, 2010. Disponível em: $\langle$ http://livros01.livrosgratis.com.br/cp152695.pdf $>$. Acesso em ou. 2017.

ICHIHARA, Y. Direito tributário: atualizado pela nova Constituição. 3. ed. São Paulo: Atlas, 1991. 
MACHADO, Hugo de Brito. Curso de Direito Tributário. 28ª ed. São Paulo: Malheiros, 2007.

MINAYO, M.C.S.(Org) Pesquisa Social; Teoria Método e Criatividade. 29a Ed. Petrópolis: Vozes, 2010

ORSINI, Caio Saab. A Significância do Planejamento Tributário para a Estrutura de Custos de uma Organização. XXIII Congresso Brasileiro de Custos - Porto de Galinhas, PE, Brasil, 16 a 18 de novembro de 2016. Disponível em:< https://anaiscbc.emnuvens.com.br/anais/article/download/4155/4156>. Acesso em: nov. 2017.

OLIVEIRA, J. R. A.; COSTA, T. F. M. Instituições de direito público e privado. Florianópolis : Departamento de Ciências da Administração / UFSC; [Brasília] : CAPES : UAB, 2010.

PÁDUA, Elisabete Matallo Marchesini de. Metodologia da Pesquisa. 10 ed. rev. e atual. Campinas: Papirus, 2004

RIZZI, Ângela Onzi. Limites do Planejamento Tributário: Diferenças entre Elisão e Evasão Fiscal. Conteudo Juridico, Brasilia-DF: 07 fev. 2014. Disponivel em: <http://www.conteudojuridico.com.br/?artigos\&ver=2.46906\&seo=1>. Acesso em: 15 nov. 2017.

SIQUEIRA, E. B; CURY, L. K. P; GOMES, T. S. Planejamento tributário. Revista CEPPG-CESUCCentro de Ensino Superior de Catalão, Ano XIV, N 25- $2^{\circ}$ Semestre/2011.

SINPROFAZ, Sindicato Nacional dos Procuradores da Fazenda Nacional. Presidente do sinprofaz revela números da sonegação em audiência na câmara. 2016. Disponível em:< http://www.sinprofaz.org.br/noticias/presidente-do-sinprofaz-revela-numeros-da-sonegacao-emaudiencia-na-camara/>. Acesso em out. 2017.

SOUZA, L. R. B. de; PAVÃO. A necessidade do planejamento tributário visando a redução dos custos nas organizações. Disponível em: $<$ https://www.inesul.edu.br/revista/arquivos/arqidvol_19_1346771456.pdf>. Acesso em out. 2017.

\section{Como citar este artigo (Formato ABNT):}

OLIVEIRA, Gilmar Gomes de; ANTUNES, Emanoel Silva. A Gestão Tributária no Controle à Sonegação Fiscal. Id on Line Revista Multidisciplinar e de Psicologia, 2018, vol.12, n.41, p.52-65. ISSN: 1981-1179.

Recebido: 07.06.2018

Aceito: 08.06.2018 